\title{
Perencanaan Strategis Menuju Webometrics Dan 4ICU Pada Website Perguruan Tinggi
}

\author{
Putu Andhika Kurniawijaya ${ }^{1}$, Dewa Made Wiharta ${ }^{2}$, Nyoman Putra Sastra ${ }^{3}$ \\ [Submission: 19-01-2019, Accepted:127-04-2019]
}

\begin{abstract}
The increasing influence of the Information and Communication Technology development requires education institution more creative in innovation and try to improving themselves and their competitiveness by applying technology in the global way. The most frequently reference materials instrument used by Indonesian and others education institution to evaluate performance and productivity based on website is appraisers, including World University database namely Webometrics and 4ICU. There are some differences regarding to the indicators used by those two ranking databases. The difference was certainly able to resulting different education institution ranking. The purpose of this study is to devise a strategic plan policy which is capable to be a guidelines for local colleges in improving its quality into the global competition. Based on the results of the Spearman Rank calculation, found that the value coefficient correlation of 0,867 (very strong). Based on the correlation or relationship between indicators and 4ICU Webometrics rating, found that backlinks and the number of scientific publications are some factors that affects the ranking.
\end{abstract}

Keywords : 4ICU, College Website, Strategic Planning, Spearman Rank, Webometrics

Intisari- Pengaruh perkembangan Teknologi Informasi dan Komunikasi (TIK) yang makin pesat menuntut perguruan tinggi untuk semakin kreatif berinovasi dalam upaya mengembangkan diri dan meningkatkan daya saingnya melalui pemanfaatan teknologi secara global. Instrumen yang paling sering digunakan oleh perguruan tinggi Indonesia maupun dunia sebagai bahan rujukan untuk mengevaluasi performa dan produktivitas berdasarkan website yang dimilikinya adalah melalui database penilai universitas dunia, diantaranya yaitu Webometrics dan 4ICU. Terdapat sejumlah perbedaan terkait indikator yang digunakan oleh kedua database pemeringkatan tersebut. Perbedaan itu tentu saja berpotensi menghasilkan penentuan ranking perguruan tinggi yang juga berbeda. Tujuan dari penelitian ini adalah menyusun rencana strategis kebijakan yang mampu menjadi pedoman bagi perguruan tinggi lokal dalam meningkatkan kualitasnya untuk menghadapi persaingan global. Berdasarkan hasil perhitungan Spearman Rank, maka diperoleh nilai koefisiensi korelasi sebesar 0.867 (sangat kuat). Berdasarkan korelasi atau hubungan antar indikator-indikator pemeringkat Webometrics dan 4ICU, backlinks dan jumlah publikasi ilmiah merupakan faktor yang mempengaruhi kedua pemeringkatan tersebut.

Kata Kunci- 4ICU, Perencanaan Strategis, Spearman Rank, Website Perguruan tinggi, Webometrics.

\footnotetext{
${ }^{1}$ Mahasiswa, Magister Teknik Elektro,Program Pascasarjana Universitas Udayana, e-mail:andhikakurnia@undhirabali.ac.id)

${ }^{2,3}$ Staff Pengajar, Magister Teknik Elektro,Program Pascasarjana Universitas Udayana, email: wiharta@unud.ac.id ${ }^{2}$, putra.sastra@unud.ac.id ${ }^{3}$
}

\section{PENDAHULUAN}

Menentukan peringkat suatu perguruan tinggi bukan pekerjaan yang mudah. Perguruan tinggi merupakan institusi dengan struktur organisasi dan tata kelola yang lebih kompleks dibandingkan institusi lainnya di bidang pendidikan. Menurut reff[1] menjelaskan evaluasi terhadap performa dan produktivitas dari suatu perguruan tinggi harus mempertimbangkan seluruh kegiatan akademik beserta output yang dihasilkan dan dampaknya secara internal maupun eksternal. Keinginan setiap perguruan tinggi untuk menjadi yang terbaik dalam kancah persaingan global mendorong perguruan tinggi terus melakukan perbaikan dan pengembangan dengan semakin mengedepankan riset dan inovasi pengajaran sebagai strategi peningkatan mutu dan kualitas menuju tingkatan perguruan tinggi bertaraf internasional (world class university).

Pengaruh perkembangan Teknologi Informasi dan Komunikasi (TIK) yang makin pesat menuntut perguruan tinggi untuk semakin kreatif berinovasi dalam upaya mengembangkan diri dan meningkatkan daya saingnya melalui pemanfaatan teknologi secara global. Implementasi TIK yang efisien serta relatif tak membutuhkan biaya terlalu besar membuka alternatif baru bagi perguruan tinggi dunia untuk meningkatkan daya saingnya. Salah satu bentuk implementasi TIK yang telah banyak diadopsi dan digunakan oleh perguruan tinggi dunia saat ini adalah website. Perkembangan teknologi internet dan kebutuhan akan layanan informasi yang kian tinggi memunculkan berbagai website baru[2]. Website telah menjadi salah satu media komunikasi efektif bagi perguruan tinggi untuk mendorong semua kegiatan akademiknya berupa pendidikan, penelitian serta transfer pengetahuan[3]. Perguruan tinggi di Indonesia sebagai bagian dari institusi pendidikan yang berusaha meningkatkan daya saing secara global melalui pemanfaatan TIK telah menyadari pentingnya website sebagai komponen kunci penilaian dalam upaya mensejajarkan diri sebagai perguruan tinggi bertaraf global. Instrumen yang paling sering digunakan oleh perguruan tinggi Indonesia maupun dunia sebagai bahan rujukan untuk mengevaluasi performa dan produktivitas berdasarkan website yang dimilikinya adalah melalui database penilai universitas dunia, diantaranya yaitu Webometrics dan $4 I C U$.

Adapun benang merah yang menghubungkan antar Webometrics dan 4ICU adalah keduanya bertujuan membantu perguruan tinggi dalam menganalisis kualitas trafik layanannya dibidang publikasi ilmiah agar mampu bersaing dalam ranah global dan tentunya menjadi lebih baik. Meskipun demikian, terdapat sejumlah perbedaan terkait indikator yang digunakan oleh kedua database pemeringkatan 
tersebut. Perbedaan itu tentu saja berpotensi menghasilkan penentuan ranking perguruan tinggi yang juga berbeda. Banyaknya perguruan tinggi Indonesia yang menggunakan kedua database pemeringkat tersebut sebagai bahan rujukan menyebabkan tiap perguruan tinggi dapat mengklaim dirinya berada pada peringkat atas sesuai rujukan yang digunakannya. Hal ini berpotensi menimbulkan perdebatan internal dalam proses penyusunan kebijakan perguruan tinggi akibat perbedaan rujukan database pemeringkat yang digunakan. Hal tersebut tentu dapat menghambat perkembangan perguruan tinggi menuju ranah persaingan global jika perdebatan terus mengemuka tanpa menghasilkan solusi konkrit.

Oleh karena itu, perlu dilakukan penelitian lebih lanjut mengenai hubungan antar indikator yang digunakan pada kedua database penilai tersebut untuk menyusun rencana strategis kebijakan yang mampu menjadi pedoman bagi perguruan tinggi lokal dalam meningkatkan kualitasnya untuk menghadapi persaingan global.

\section{TinjauAn Pustaka}

\section{A. Perencanaan Strategis}

Perencanaan strategis merupakan strategi sebagai seperangkat keputusan dan tindakan yang menghasilkan formulasi dan implementasi dari rencana yang didesain untuk mencapai tujuan[4].

Perencanaan strategis berkaitan dengan dampak masa depan, dan keputusan strategis yang dibuat sekarang. Perencanaan itu mencakup beberapa pilihan yang berkaitan dengan organisasi secara keseluruhan. Perencanaan strategis pada hakekatnya merupakan proses secara sistematis yang berkelanjutan dari pembuatan keputusan yang memiliki resiko, dengan memanfaatkan sebanyak-banyaknya pengetahuan antisipatif, mengorganisasi secara sistematis usaha-usaha melaksanakan keputusan tersebut dan mengukur hasilnya melalui umpan balik yang terorganisasi dan sistematis.

\section{B. Webite}

Website merupakan kumpulan halaman-halaman yang digunakan untuk menampilkan informasi teks, gambar diam atau gerak, animasi, suara, dan atau gabungan dari semuanya, baik yang bersifat statis maupun dinamis yang membentuk satu rangkaian bangunan yang saling terkait, yang masingmasing masing dihubungkan dengan jaringan-jaringan halaman[5].

\section{Perguruan Tinggi}

Perguruan tinggi menurut reff[6] adalah satuan pendidikan yang padanya diselenggarakan jenjang pendidikan tinggi di mana peserta didiknya disebut mahasiswa, sedangkan tenaga pendidiknya disebut dosen. Disebutkan pula perguruan tinggi terdiri dari dua jenis, yaitu perguruan tinggi negeri dan perguruan tinggi suasta. Yang mana perbedaannya adalah terletak pada yang berwenang dalam pengelolaan dan peregulasian yang dilakukan.

\section{Webometrics}

Webometrics merupakan salah satu indikator online untuk mengukur kemajuan perguruan tinggi dan melakukan pemeringkatan terhadap ranking website perguruan tinggi dunia. Webometrics juga merupakan inisiatif untuk mempromosikan publikasi ilmiah guna meningkatkan kehadiran akademik dan lembaga- lembaga penelitian di situs web.

Berdasarkan model pemeringkatan yang dibangun[7], terdapat empat indikator utama yang digunakan oleh webometrics untuk menentukan ranking suatu perguruan tinggi, yaitu:

\section{1) Visibility}

Data link visibility memiliki bobot $50 \%$ diperoleh dari dua penyedia informasi utama yaitu Majestic SEO dan ahrefs. Kedua penyedia informasi tersebut memiliki crawler tersendiri yang menghasilkan database berbeda dan dapat digabungkan bersama untuk menutupi perbedaan yang muncul diantara keduanya atau untuk mengoreksi kesalahan satu sama lain. Prosedur dalam visibility ini meliputi proses ekstraksi total jumlah external inlink (dikenal juga sebagai backlinks) serta jumlah total webdomain dimana link-link tersebut berasal (dikenal juga sebagai referring domains).

\section{2) Presence}

Total jumlah halaman web yang dimuat pada webdomain utama perguruan tinggi (termasuk seluruh subdomain dan direktori) sebagaimana yang terindeks oleh search engine komersil terbesar yaitu Google.

3) Opennes

Indikator yang menghitung total banyaknya file publikasi akademik yang terindeks pada Google Scholar, yaitu search engine akademik terbesar yang memiliki data lebih dari 160 juta catatan publikasi file akademik.

4) Excellence

Indikator ini menghitung jumlah total tulisan-tulisan ilmiah (scientific papers) yang terdaftar pada jurnal ilmiah internasional yang memiliki high impact. Kategori tulisan ilmiah perguruan tinggi yang dapat diperhitungkan dalam indikator ini adalah top $10 \%$ tulisan ilmiah yang paling banyak dikutip berdasarkan bidang ilmu dari penyedia data yang ditentukan, yaitu Scimago data.

\section{E. $4 I C U$}

Situs pemeringkat 4ICU merupakan search engine dan direktori pendidikan tinggi yang melakukan tinjauan terhadap Universitas dan Kampus terakreditasi di seluruh dunia. Berbeda dengan webometrics, metrik pengukuran yang digunakan oleh $4 I C U$ untuk melakukan pemeringkatan perguruan tinggi didasarkan pada kepopuleran situs web dari 11.606 Universitas dan Kampus di 200 negara[8].

Adapun metode pemeringkatan yang digunakan oleh 4ICU didasarkan pada algoritma yang melibatkan empat non bias webometrics independen yang diekstraksi dari tiga search engine berbeda yaitu Google Page Rank, Alexa Global Rank, dan Majestic SEO (Referring Subnets dan Trust Flow). Ada kebijakan khusus yang dilakukan oleh 4ICU di dalam melaksanakan penilaian pada perguruan tinggi di seluruh dunia. Kebijakan tersebut dilakukan mengingat yang dinilai 
DOI: https://doi.org/10.24843/MITE.2019.v18i01.P14

oleh 4ICU adalah kepopuleran alamat situs resmi milik perguruan tinggi, sehingga $4 I C U$ tidak memberitahukan cara penilaian yang dilakukannya guna menghindari kecurangan yang dilakukan webmaster perguruan tinggi dalam meningkatkan peringkat perguruan tinggi masing-masing.

Pemeringkatan 4ICU juga merupakan bentuk benchmarking untuk media online. 4ICU lebih menitikberatkan pada jumlah pengunjung yang mengakses website, serta tautan dari situs lain. Banyaknya pengunjung memang belum tentu identik dengan mutu konten dari website. Namun tidak dapat dipungkiri, bahwa teknik-teknik SEO sering diterapkan oleh para pengelola website kampus agar website ramah terhadap mesin pencari, dengan sasaran akhirnya website banyak dikunjungi, bahkan ada yang berusaha menitip link atau blog walking agar bisa meningkatkan potensi kunjungan ke website.

\section{F. Spearman Rank}

Metode korelasi Spearman Rank adalah ukuran asosiasi yang menuntut kedua variabel diukur sekurang-kurangnya dalam skala ordinal sehingga objek-objek atau individuindividu yang dipelajari dapat di ranking dalam dua rangkaian berurut. Jadi metode korelasi Spearman Rank adalah metode yang bekerja untuk skala data ordinal atau rangking dan bebas distribusi. Menurut reff[9] rumus korelasi yang digunakan adalah sebagai berikut :

$$
r_{s}=1-\frac{6 \sum b i^{2}}{n\left(n^{2}-1\right)}
$$

Nilai korelasi Spearman Rank berada diantara -1 s/d 1. Bila nilai $=0$, berarti tidak ada korelasi atau tidak ada hubungannya antara variabel independen dan dependen. Nilai $=+1$ berarti terdapat hubungan yang positif antara variabel independen dan dependen. Nilai $=-1$ berarti terdapat hubungan yang negatif antara variabel independen dan dependen.

TABEL I

Makna Nilai Korelasi Rank Spearman

\begin{tabular}{|c|c|}
\hline \multicolumn{2}{|c|}{ Makna Nilai Korelasi Rank Spearman } \\
\hline $0,00-0,19$ & Makna \\
$0,20-0,39$ & Sangat lemah \\
$0,40-0,59$ & Lemah \\
$0,60-0,79$ & Sedang \\
$0,80-1,00$ & Kuat \\
\hline
\end{tabular}

Menurut reff[9] menjelaskan, untuk menguji hipotesis tersebut serta mengetahui korelasi kedua variabel signifikan atau tidak dengan menguji uji t .Rumus yang dapat digunakan untuk mencari $t_{\text {hitung }}$ adalah sebagai berikut :

$t_{\text {hitung }}=\frac{r_{s \sqrt{n-2}}}{1-r_{s}^{2}}$

\section{Metodology Penelitian}

\section{A. Pendekatan Penelitian}

Putu Andhika Kurniawijaya: Perencanaan Strategis Menuju Webometrics...
Pendekatan yang digunakan pada penelitian ini adalah pendekatan deskriptif kualitatif, yaitu pendekatan yang mengacu pada teori serta teknik penyusunan yang diperoleh berdasarkan studi kepustakaan (literature study) dari hasil penelitian terkait sebelumnya serta analisis terhadap data yang diperoleh, dalam hal ini berupa hasil penelusuran dari situs pemeringkat Webometrics dan 4ICU.

Pendekatan kualitatif digunakan karena parameter pengujian yang diamati merupakan variabel yang tidak memiliki batasan jelas secara kuantitatif, namun memiliki pengaruh besar pada proses pemeringkatan website perguruan tinggi Indonesia yang dihasilkan oleh Webometrics dan 4ICU.

\section{B. Populasi dan Sampel Penelitian}

Metode pemilihan sampel yang dipakai adalah metode non random sampling menggunakan teknik purposive sampling. Teknik purposive sampling biasanya digunakan oleh peneliti jika peneliti memiliki pertimbangan-pertimbangan tertentu dalam pengambilan sampelnya. Adapun sampel utama dalam penelitian ini berdasarkan pada data pemeringkaatan yang dipublish oleh situs pemeringakatan website perguruan tinggi yaitu pemeringakatan Webometrics dan pemeringakatan 4ICU.

TABEL II

Populasi dan Sampel

\begin{tabular}{|l|c|c|c|}
\hline \multicolumn{1}{|c|}{$\begin{array}{c}\text { Kelompok } \\
\text { populasi }\end{array}$} & $\begin{array}{c}\text { Jumlah } \\
\text { Populasi }\end{array}$ & $\begin{array}{c}\text { Penentuan } \\
\text { sampel }\end{array}$ & $\begin{array}{c}\text { Jumlah } \\
\text { Sampel }\end{array}$ \\
\hline $\begin{array}{l}\text { Kelompok PT } \\
\text { peringkat }\end{array}$ & 100 & $\begin{array}{c}10 \% \mathrm{x} \\
\text { Populasi }\end{array}$ & 10 \\
Webometric & 100 & $\begin{array}{c}10 \% \mathrm{x} \\
\text { Populasi }\end{array}$ & 10 \\
\hline $\begin{array}{l}\text { Kelompok PT } \\
\text { peringkat } \\
\text { 4ICU }\end{array}$ & & 20 \\
\hline \multicolumn{4}{|l|}{} \\
\hline
\end{tabular}

\section{Pengolahan dan Analisis Data}

Alur analisis data dalam penelitian ini mengikuti model analisis interaktif sebagaimana diungkapkan Miles dan Huberman[10]. Proses yang dilakukan setelah pengumpulan data adalah data yang didapat akan dipilah-pilah sesuai dengan kebutuhan dalam penelitian ini selanjutnya dilakukan proses reduksi data yang relevan untuk memecahkan permasalahan yang ada. Kemudian menyederhanakan dan menyusun secara sistematis dan menjabarkan hal-hal penting tentang hasil temuan dan maknanya. Pada proses reduksi data, hanya temuan data atau temuan yang berkenaan dengan permasalahan penelitian saja yang direduksi.

\section{HASIL DAN PEMBAHASAN}

\section{A. Analisis Korelasi Pemeringkatan Webometrics dan 4ICU Menggunakan Uji Korelasi Spearman Rank}

Analisis korelasi pemeringkatan digunakan untuk mengetahui bagaimana hubungan indikator-indikator penilaian pemeringkatan webometrics dan 4ICU. Analisis dilakukan dengan melakukan pengujian indikator penilaian antara indikator penialaian webometrics dan indikator 
penilaian 4ICU yang diuji menggunakan uji korelasi Spearman Rank. Analisa korelasi spearman rank digunakan untuk mengukur derajat keeratan hubungan antar indikator hasil pemeringkatan webometrics dan 4ICU. Hasil dari uji Spearman Rank nantinya akan dapat ditarik kesimpulan bagaimana hubungan anatara indikator penialaian webometrics dengan indikator penilaian 4ICU. Berikut hasil analisis Koefesien Korelasi Spearman Rank digunakan dengan program SPSS versi 24.

TABEL III

Hasil uji korelasi spearman rank Webometrics dan 4ICU menggunakan SPSS versi 24

\begin{tabular}{|l|l|r|r|}
\hline \multicolumn{2}{|c|}{ Spearman's rho } & 4ICU & $\begin{array}{c}\text { WEBOMETR } \\
\text { ICS }\end{array}$ \\
\hline \multirow{2}{*}{ 4ICU } & $\begin{array}{l}\text { Correlation } \\
\text { Coefficient }\end{array}$ & 1.000 & $.867^{* *}$ \\
\cline { 2 - 4 } & $\begin{array}{l}\text { Sig. (2- } \\
\text { tailed) }\end{array}$ &. & .001 \\
\cline { 2 - 4 } & $\mathrm{N}$ & 10 & 10 \\
\hline \multirow{2}{*}{$\begin{array}{l}\text { MEBO } \\
\text { CS }\end{array}$} & $\begin{array}{l}\text { Correlation } \\
\text { Coefficient }\end{array}$ & $.867^{* *}$ & 1.000 \\
\cline { 2 - 4 } & $\begin{array}{l}\text { Sig. (2- } \\
\text { tailed) }\end{array}$ & .001 & \\
\cline { 2 - 4 } & $\mathrm{N}$ & 10 & \\
\hline
\end{tabular}

Berdasarkan hasil perhitungan uji Spearman Rank yang dilakukan maka dapat diperoleh nilai koefisiensi korelasi sebesar 0.867 dengan taraf signifikansi untuk hipotesis umum sebesar 0.001 dengan signifikansi sebesar $0.001<0.005$. Hasil tersebut menunjukkan adanya hubungan yang signifikan antara indikator penilaian perankingan webometrics dengan indikator perankingan 4ICU. Hubungan ini ditunjukan dengan hasil nilai uji korelasi sebesar 0.867 yang termasuk kedalam kategori sangat kuat dengan skala (0.800-1.000).

\section{B. Korelasi Indikator Pemeringkatan Webometrics dan 4ICU}

Setelah dilakukan uji korelasi menggunakan spearman rank didapat hasil bahwa ada hubungan antara indikator penialaian webometrics dengan indikator penialian 4ICU. Dari hal tersebut didapat bahwa hubungan yang terjadi akan menjadi pedoman untuk melakukan perencanaan strategis untuk meningkatkan daya saing dalam pemeringakatan website perguruan tinggi baik dalam pemeringakatan webometrics maupun pemeringkatan 4ICU. Keterkaitan indikator-indikator tersebut akan mejadi langkah strategis kedepan bagi perguruan tinggi dimana dalam upaya meningkatkan daya saing dalam pemeringkatan dilakukan dengan satu langkah strategis untuk bisa bersaing di dua pemeringkatan.Hubungan antara indikator penilaian webometrics dan indikator penilaian $4 I C U$ dibuat dalam bentuk diagram alur seperti yang ditampilkan pada gambar dibawah ini.

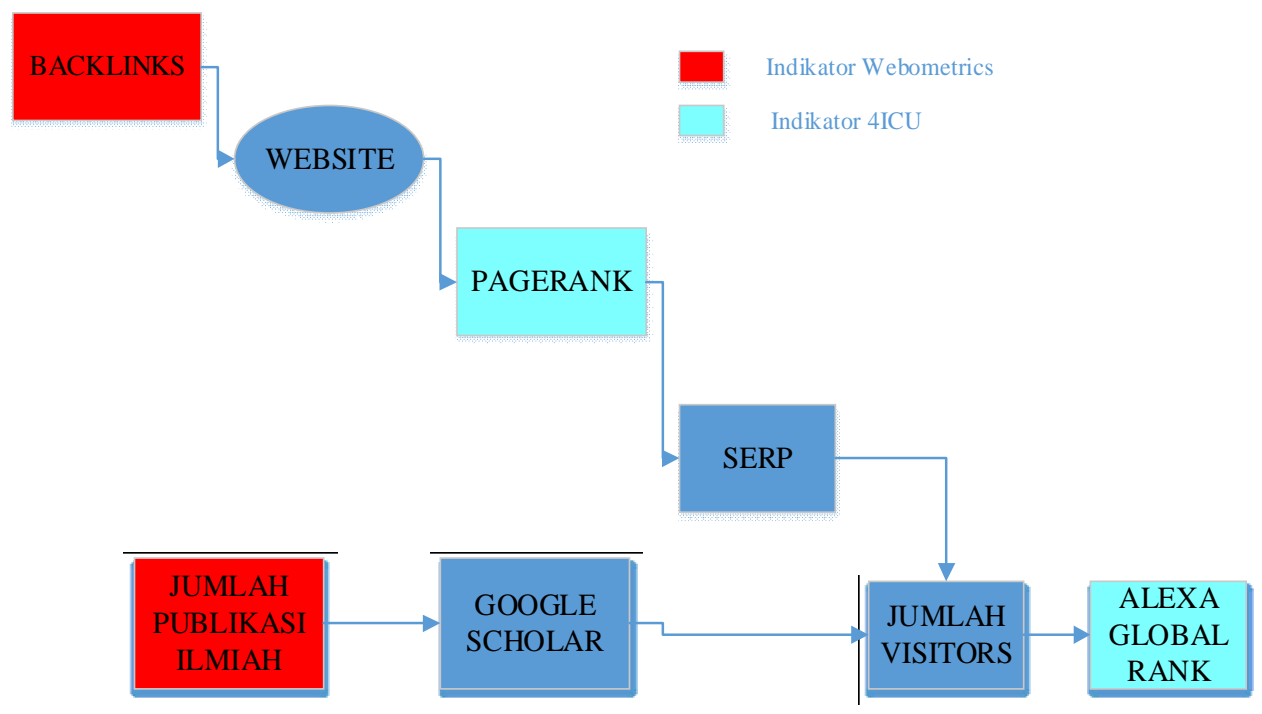

Gambar 1. Korelasi indicator pemeringkatan Webometrics dan 4ICU

Dari alur yang disampaikan diatas dapat dilihat bahwa ada korelasi atau hubungan yang terkait antara indikator penilaian webometrics dan indikator penilaian $4 I C U$ yaitu indikator backlinks dengan pagerank yang berpengaruh terhadap posisi peringkat pada mesin pencari serta indikator jumlah publikasi ilmiah yang berpengaruh pada jumlah visitor website perguruan tinggi.

1) Korelasi indikator backlinks dengan pagerank terhadap SERP 
Pada alur yang disampaikan dapat dilihat bagaimana keterkaitan antatra indikator penilaian webometrics dan indikator penilaian $4 I C U$, dimana diambil indikator yang sangat berpengaruh yaitu indikator backlinks dan indikator jumlah publikasi ilmiah. Data backlinks website perguruan tinggi didapat menggunakan Majestics dan Ahrefs yang merupakan tools online untuk mendapatkan informasi jumlah backlinks dari website perguruan tinggi. Backlinks merupakan suatu tautan yang terletak diluar website perguruan tinggi yang kita kelola dan mengarah kembali atau disebut dengan feedback. Dari alur korelasi yang didapat terlihat bahwa jumlah backlinks yan mengarah pada website perguruan tinggi mempengaruhi PageRank. PageRank merupakan suatu penilaian ranking yang dikeluarkan oleh Google dengan unsur utama penialaian kulaiatas backlinks, pagerank pada website ditunjukkan dengan skala skala 0 sampai dengan 10 sesuai dengan standar kualiats backlinks yang dinilai. Pengaruh PageRank terhadap website perguruan tinggi adalah semakin tinggi nilai PageRank yang diperoleh akan semakin baik prioritas website perguruan pada posisi Search Engine Result Page (SERP) mesin pencari berdasarakan keyword yang dicari oleh pengunjung. Jumlah visitor yang dating ke website perguruan tinggi akan mempengaruhi peringkat alexa rank, karena penilaian dari Alexa berdasarkan jumlah visitor dan daily pageviews website perguruan tinggi.

2) Korelasi jumlah publikasi ilmiah dengan jumlah visitor terhadap alexa rank

Salah satu indikator penilaian webometrics adalah opennes. Openness merupakan banyaknya jumlah file publikasi perguruan tinggi yang terindeks kedalam Google Scholar. File publikasi tersebut akan meningkatkan jumlah visitors sehingga semakin banyak jumlah publikasi yang terindeks Google Scholar semakin banyak pula jumlah visitors. Dengan pengimplementasian backlinks pada website maka akan meningkatakan SERP pada mesin pencari. Posisi rangking pada mesin pencari berdasarkan keyword yang dicari oleh pengunjung/visitors akan mempengaruhi jumlah visitors ke website dan otomatis berpengaruh pada daily pageviews per visitors. Jumlah visitors mempengaruhi ranking pada alexa rank, semakin banyak visitors perhari (daily pageviews per visitors) akan meningkatkan alexa rank.

Dari gambaran alur korelasi yang terjadi dapat ditarik kesimpulan bahwa keterkaitan indikator penilaian antara webometrics dengan 4ICU dapat dijadikan rencana strategis kedepan untuk meningkatkan daya saing khususnya pemeringkatan website perguruan tinggi. Fokus rencana strategis bisa dilakukan untuk meningkatkan backlinks baik dari segi kualitas maupun jumlah backlinks yang mengarah pada website perguruan tinggi serta meningkatkan jumlah publikasi karya ilmiah yang diharapkan bisa terindeks pada Google Scholar.

\section{Strategi Peningkatan Backlinks}

Setelah didapatkan hubungan keterkaitan antara indikator penilaian webometrics dan indikator penilaian $4 I C U$, maka dapat dirumuskan rencana strategis kedepan yang bisa dilakukan serta tujuan yang ingin diharapkan dari strategi yang dilakukan. Rencana strategis dalam peningkatan indikator backlinks dapat dapat dijelaskan sebagai berikut.

TABEL IV

Strategi peningkatan backlinks dan indikator yang diharapkan

\begin{tabular}{|l|l|}
\hline \multicolumn{1}{|c|}{$\begin{array}{c}\text { Strategi Peningkatan } \\
\text { Baclinks }\end{array}$} & Indikator yang diharapkan \\
\hline $\begin{array}{l}\text { Membangun backlinks } \\
\text { dengan mencari links yang } \\
\text { relevan }\end{array}$ & $\begin{array}{l}\text { Semakin banyak backlinks } \\
\text { yang didapat dari website } \\
\text { dengan topik pendidikan }\end{array}$ \\
\hline $\begin{array}{l}\text { Diupayakan backlinks yang } \\
\text { berasal dari contextual links }\end{array}$ & $\begin{array}{l}\text { Semakin banyak konten baik } \\
\text { dari dalam atau luar } \text { website } \\
\text { yang memberikan backlinks } \\
\text { ke website perguruan tinggi. }\end{array}$ \\
\hline $\begin{array}{l}\text { Diupayakan backlinks yang } \\
\text { berasal dari High PageRank } \\
\text { (PR) }\end{array}$ & $\begin{array}{l}\text { Semakin banyak jumlah } \\
\text { backlinks dari website yang } \\
\text { berpagerank tinggi }\end{array}$ \\
\hline $\begin{array}{l}\text { Baclinks yang berasal dari } \\
\text { established domain }\end{array}$ & $\begin{array}{l}\text { Peningkatan jumlah backlinks } \\
\text { yang berasal dari domain yang } \\
\text { sudah mempunyai umur }\end{array}$ \\
\hline $\begin{array}{l}\text { Agar memperhatikan } \\
\text { kualitas dari alexa trafik } \\
\text { rank. }\end{array}$ & $\begin{array}{l}\text { Peningkatan jumlah } \\
\text { kunjungan ke website } \\
\text { perguruan tinggi. }\end{array}$ \\
\hline $\begin{array}{l}\text { Menghindari low Outbond } \\
\text { link }\end{array}$ & $\begin{array}{l}\text { Meminimalisir links yang } \\
\text { mengarah keluar }\end{array}$ \\
\hline $\begin{array}{l}\text { Mencari backlinks dari } \\
\text { website yang mempunyai } \\
\text { attribut Dofollow dan } \\
\text { menghindari attribut } \\
\text { nofollow }\end{array}$ & $\begin{array}{l}\text { Mendapatkan kualitas } \\
\text { backlinks yang baik }\end{array}$ \\
\hline Prioritas pada One Way Link & $\begin{array}{l}\text { Meminimalisir broken link } \\
\text { atau link yang rusak }\end{array}$ \\
\hline
\end{tabular}

Dalam tabel IV diatas menjelaskan beberapa rencana strategis yang bisa dilakukan kedepan serta capaian yang ingin didapat. Secara umun strategi yang dilakukan fokus pada peningkatan jumlah backlinks, peningkatan kualitas backlinks, strategi DoFollow backlinks dan peningkatan pagerank.

\section{Strategi Peningkatan Jumlah Publikasi Ilmiah}

Strategi selanjutnya yang dilakukan kedepan untuk meningkatkan daya saing pemeringkatan website perguruan tinggi adalah peningkatan indikator jumlah publikasi ilmiah, berupa karya ilmiah maupun artikel ilmiah yang terindeks pada Google Scholar. Rencana strategis untuk meningkatkan jumlah publikasi karya ilmiah dapat dijelaskan sebagai berikut.

TABEL V

Strategi peningkatan jumlah file publikasi dan indikator yang ingin dicapai

\begin{tabular}{|c|c|}
\hline $\begin{array}{c}\text { Strategi peningkatan } \\
\text { jumlah file publikasi }\end{array}$ & $\begin{array}{c}\text { Indikator yang ingin } \\
\text { dicapai }\end{array}$ \\
\hline Membangun repository & Manajemen pengelolan \\
\hline
\end{tabular}




\begin{tabular}{|l|l|}
\hline & file publikasi yang baik \\
\hline $\begin{array}{l}\text { Memperbanyak konversi } \\
\text { file publikasi ilmiah }\end{array}$ & $\begin{array}{l}\text { Semakin banyak file } \\
\text { yang terindek oleh } \\
\text { search engine google } \\
\text { dan google scholar }\end{array}$ \\
\hline Policy penelitian & $\begin{array}{l}\text { Pedoman bagi penulis } \\
\text { karya ilmiah sebelum } \\
\text { dipublikasikan }\end{array}$ \\
\hline
\end{tabular}

Dari tabel V diatas dijelaskan beberapa strategi peningkatan jumlah publikasi karya ilmiah beserta tujuan yang dingin dicapai diantaranya membangun repository sebagai media penyimpanan online file karya ilmiah perguruan tinggi serta dilakukan kebijakan internal berupa policy dan aturan mengenai standar publikasi ilmiah.

\section{KESIMPULAN}

Dari analisa korelasi spearman rank dapat disimpulkan bahwa webometrics dan 4ICU memiliki nilai korelasi sebesar 0,867 yang termasuk dalam kategori hubungan yang sangat kuat. Berdasarkan korelasi atau hubungan antar indikatorindikator pemeringkat webometrics dan 4ICU,didapat hasil bahwa indikator penilaian backlinks dan jumlah publikasi ilmiah merupakan faktor yang mempengaruhi pemeringkatan tersebut. Backlinks yang merupakan indikator dari webometrics pada website perguruan tinggi berpengaruh pada MajesticSEO, PageRank dan Alexa Global Rank dari indikator penilaian 4ICU. Jumlah publikasi ilmiah merupakan salah satu dari faktor penentu pemeringkatan webometrics yaitu openness yang menekankan jumlah file publikasi ilmiah yang terindek pada search engine pada google scholar. Jumlah publikasi ilmiah pada website perguruan tinggi akan berpengaruh pada jumlah visitors, dimana indikator visitors berpengaruh pada Alexa Global Rank yang merupakan indikator penilaian dari 4ICU. Rekomandasi dan usulan strategi pemeringkatan webometrics dan 4ICU diutamakan pada faktor yang paling berpengaruh pada kedua pemeringkatan yaitu peningkatan jumlah backlinks dan peningkatan jumlah file publikasi ilmiah agar lebih terindeks oleh mesin pencari google dan google scholar. Strategi peningkatan jumlah backlinks dilakukan dengan mencari link yang relevan, backlinks yang berasal dari contextual link, backlinks dengan High PageRank (PR), backlinks yang berasal dari established domain, memperhatikan kualitas alexa traffik rank, menghindari outbond link, dan prioritas link satu arah (one way link). Strategi pada peningkatan jumlah file publikasi ilmiah dilakukan dengan membangun repositori, memperbanyak konversi file publikasi ilmiah dan policy penelitian.

\section{REFERENSI}

[1] Viloria, A., Samuel, M. T., Vásquez, C. L., Varela, N., Cabrera, D., \& Gaitán-Angulo, M. (2016). Ranking of scientific visibility of Latin American universities. Journal of Control Theory and Applications. ISSN, 0974-5572.

[2] Nyoman Purnama, I Ketut Gede Darma, Putu Agung Bayupati, "Klasifikasi Website Menggunakan Algoritma Multilayer Perceptron", Majalah Ilmiah Teknologi Elektro Udayana, Vol.13, No.2, JuliDesember 2014.

[3] Viloria, A., Varela, N., Hernández-Fernandez, L., \& Portillo-Medina, R. (2018, June). Analysis of Patterns in the University World Rankings Webometrics, Shanghai, QS and SIR-SCimago: Case Latin America. In Data Mining and Big Data: Third International Conference, DMBD 2018, Shanghai, China, June 17-22, 2018, Proceedings (Vol. 10943, p. 188). Springer..

[4] Solihin, I. P., \& Wibisono, M. B. (2017). Perencanaan Strategik Sistem Informasi Dan Teknologi Informasi (Si/Ti) Dengan Framework Zachman Di Universitas Pembangunan Nasional Veteran Jakarta. Semarang, 11 november 2017, Prosiding Vol 1.

[5] Bekti, H. B. (2015). Mahir Membuat Website dengan Adobe Dreamweaver CS6, CSS, dan Jquery. Yogyakarta: CV Andi Offset.

[6] Nano Supriono, "Arti Perguruan Tinggi," http://www. id.shvoong.com/social-sciences/education/2124265-arti-perguruantinggi, (diakses tanggal 1 desember 2018).

[7] Aguillo, I, Methodology. http://webometrics.info/en/Methodology, (diakses tanggal 28 mei 2017).

[8] Higher Education Institutions, http://www.4icu.org/about/ (diakses tanggal 12 Mei 2017).

[9] Sandi, D. P., Sihombing, C. N., \& Tobing, E. G. (2017). Analisis Hubungan Kompensasi Dan Motivasi Terhadap Produktivitas Kerja Karyawan Bagian Admin Di PT Dynamic Succes Globalindo. Fundamental Management Journal, 2(02), 90-103.

[10] Hasanah, H. (2017). Teknik-Teknik Observasi (Sebuah Alternatif Metode Pengumpulan Data Kualitatif Ilmu-ilmu Sosial). At-Taqaddum, $8(1), 21-46$. 